\section{What does the visual system know about words?}

THOMAS H. CARR

Michigan State University, East Lansing, Michigan 48824

ALEXANDER POLLATSEK

University of Massachusetts, Amherst, Massachusetts 02116

and

MICHAEL I. POSNER

University of Oregon, Eugene, Oregon, 97403

We would like to discuss several points raised by Henderson (1980) about lexicality effects in word perception and, in the process, address some broader issues concerning theory and method in the study of perceptual encoding mechanisms. We have argued previously (Carr, Posner, Pollatsek, \& Snyder, 1979; Pollatsek \& Carr, 1979) that available "same""different" matching data are consistent with the claim that formation of a visual code representing a word is facilitated by orthographic regularity, but that few if any data unambiguously support the claim that formation of a visual code is facilitated by familiarity or meaning. These two variables $d o$ produce effects in word processing tasks, and these effects have often been attributed to the mechanisms of visual code formation. In our opinion, however, the effects are at least as consistent with facilitation in nonvisual encoding mechanisms and criterion shifting in decision and response selection as they are with explanations in terms of visual code formation. Henderson has criticized these conclusions in a thoroughgoing manner, arguing that our experiments are insensitive to familiarity because of design. He further argues that our analysis of the literature overlooks or misinterprets a number of findings that provide quite unambiguous support for an advantage of words over pseudowords and perhaps for acronyms over nonsense-both in the matching task and in tachistoscopic recognition. According to Henderson, these findings disprove our thesis and demonstrate that lexicality is a sufficient condition for perceptual facilitation.

We believe that this dispute hinges on differences between Henderson and us in standards for evaluating evidence, strategies for using specific tasks to tap

We would like to thank Roderick W. Barron, J. Kathryn Bock, Tracy L. Brown, Leslie Henderson, and Mildred Mason for insightful comments, criticisms, and discussion during preparation of this paper. Address correspondence to Thomas H. Carr, Department of Psychology, Michigan State University, East Lansing, Michigan 48824. specific underlying mechanisms, and terminologies. The terminologies provide clues to more important distinctions in theoretical orientation. We will discuss the particulars as well as the general implications of each of these differences.

\section{Preface: The Source of the Differences}

As an introduction, we would like to argue that all of these differences between Henderson and us actually spring from a common source, a more fundamental difference in our motivations for studying word perception. Two related but distinct sets of concerns can be identified in current word processing research. The first consists of a focus on the word superiority effect as an empirical phenomenon. This focus results in attempts to define the stimulus characteristics and presentation conditions that support the occurrence of the effect. In other words, the central issue is to identify the factors that influence the latency and accuracy of decisions about letter strings made under conditions of speed stress or brief stimulus presentation. The second consists of a focus on the information processing system that underlies word superiority rather than on the phenomenon itself. This second focus results in aftempts to explicate the operation of the internal mechanisms that respond to stimulus characteristics and presentation conditions.

It appears to us that Henderson tends to focus more on the word superiority effect as an empirical phenomenon, and we tend to focus more on the characteristics of underlying processing mechanisms. This difference in focus is obvious in the introductions to our respective papers. Henderson (1980) opens with a discussion of the word superiority effect and whether lexicality produces an advantage over and above that produced by orthographic regularity in any of the tasks commonly used in this area of research. Carr et al. (1979) open with a discussion of rule-governed vs. stimulus-specific processing mechanisms and whether the effects of those two kinds of mechanisms can be isolated in visual, phonological, or semantic encoding systems. The difference in focus then manifests itself further in the more specific differences in theoretical orientations, evidential standards, and research strategies, which we will discuss in the remainder of this note.

\section{Orthography, Familiarity, Meaning, and Lexícality}

In our experiments, we attempted to separate the effects of several characteristics of words on decisions made at several levels of stimulus analysis. Specifically, we varied orthographic regularity, familiarity, and meaning in tasks based on visual, phonological, and semantic or conceptual codes, with particular attention paid to tasks based on visual codes. 
These experiments were aimed at taking apart "the word superiority effect" and mapping out the roles that different characteristics of words as stimuli play in the different mental operations by which words are perceived. Underlying this approach is the assumption that lexicality is something to be explained, and one possible explanation is that a lexical item or word is represented in part by the conjunction of (at least) three characteristics: a degree of orthographic regularity determined by the utilization of acceptable and predictable spelling patterns or approximations to them, a degree of familiarity determined by the extent of the perceiver's past experience or number of previous encounters with that particular string of letters, and a meaning consisting of a set of concepts that can be referred to by the string.

Henderson, on the other hand, wishes to make a dual rather than a triple distinction between stimulus characteristics. Word superiority effects in perceptual decision making may be due to orthographic regularity or to lexicality, where lexicality is defined as the existence in a mental lexicon of a visually addressable entry representing a word. In contrast with our position, Henderson considers "lexicality" to be a primary stimulus characteristic-things happen in the mind because of the fact, in and of itself, that a string of letters is a word, not because the string of letters possesses a number of independently identifiable characteristics that together constitute what it means to be a word.

An important theoretical distinction hangs on the difference between Henderson's way of talking about words and ours, concerning the organization of encoding mechanisms (or the model of word recognition) implied by the terminology. Our view is most compatible with a system composed of several relatively independent stimulus analyzing mechanisms operating largely in parallel, each of whose outputs is a code representing some attribute of the stimulus (e.g., its visual configuration, pronunciation, or semantic content). These codes are all available to a central decision mechanism that coordinates them in the service of a task. Which codes are attended and what relations between codes are computed depend on task requirements. This system has a strong neurobiological orientation (see Carr, 1979; Conrad, 1978; Keele \& Neill, 1979; Posner, 1978; Posner \& Rogers, 1978; Treisman \& Gelade, 1980). Henderson's view is more compatible with a system in which a contentaddressable node in a memory network represents the lexicality of a stimulus (the fact that it is a word). This node acts as a gateway to all other knowledge about the stimulus. Visual stimulation activates the node, which makes available the addresses of other memory locations at which information such as spelling, pronunciation, meaning, common usages, and past encounters in text can be found if it is desired. This system has a strong artificial intelligence orientation (see Anderson, 1976; Bobrow \& Collins, 1975; Forster, 1976; Norman \& Rumelhart, 1975; Wickelgren, 1979). Given these theoretical differences concerning the organization of encoding mechanisms, we believe that finding out whether orthography, familiarity, and meaning influence the same or different mental operations is an empirical question worth pursuing. If this question is to be answered, some ground rules must be established by which the observed influences of stimulus characteristics can be attributed to particular processing mechanisms. We therefore turn to standards for evaluating evidence about the locus of an effect produced by a stimulus variable.

\section{Standards for Evaluating Evidence}

It has become a common practice in cognitive psychology to use a tenet of signal detection theory together with parts of Sternberg's (1969) additive factors logic in order to identify the processing mechanism most likely to be affected by a particular experimental manipulation. Signal detection theory's contribution is the basic distinction between an effect on the quality of the data available to a decision maker and an effect on the criteria by which the data are judged and a response is selected from the possible alternatives. Any given manipulation could potentially affect the data, the criteria, or both. The contribution from additive factors logic is the assumption that if two variables interact, they may influence the same processing mechanism, and if they are additive, they may influence different mechanisms. This language is watered down considerably from the usual interpretation of Sternberg's (1969) position because, as was originally pointed out by Sternberg, under certain conditions additive factors could influence the same mechanism (Taylor, 1976) and interactive factors could influence different mechanisms (McClelland, 1979). Despite these complications, however, the strong form of additive factors logic still underlies most first guesses about probable loci of observed effects.

This sets the stage for a consideration of the kind of evidence that would be convincing when one wants to determine whether a variable such as familiarity influences the data on which a decision is basedthat is, code formation-or the criteria by which the decision is made. Quite simply, if better data are available, better decisions of all types should be possible. Thus, a main effect of familiarity could be taken as evidence for facilitation of code formation. Such an effect would indicate that, regardless of what was finally decided about the stimulus, processing was more efficient when the stimulus was familiar. However, if decision criteria rather than code formation were affected, then one type of decision or alternative response might be facilitated but others might remain unaffected or become inhibited, depending on the relations among alternatives and the nature of the 
mechanism that chooses them. If a bias toward one alternative can only be achieved at the expense of making other alternatives less accessible, then facilitation of one alternative would be accompanied by inhibition of the others. If decisions are accomplished through a parallel race between structures that collect data independently of one another, then facilitation of one alternative might occur with no change at all in other criteria (Anderson, 1976; Keele, 1973; Morton, 1969; Newell, 1973; Posner \& Snyder, 1975). But, regardless of the particulars, an interaction between familiarity and type of decision would be evidence that familiarity was at least affecting decision processes (cf. Meyer, Schvaneveldt, \& Rudy, 1975; Sternberg, 1969). Whether familiarity could also be said to affect the quality of data would depend on whether an interpretable main effect of familiarity occurred in addition to the interaction. By interpretable, we mean a main effect that is significant for all decision types, despite the interaction.

These are conservative standards for concluding that a variable influences code formation rather than decision mechanisms. If the standards are met, however, one can feel confident of the conclusion. Thus, we are willing to argue that orthographic regularity, which met these standards quite consistently in our experiments, facilitates code formation in the matching task. If the standards are not met, we would argue that, although it remains possible that the variable in question may influence code formation, we do not yet know unambiguously that it does. We therefore feel that the proper conclusion when the standards are not met is that, with respect 10 unambiguous evidence, the variable cannot be said to influence code formation, although future research could show that it does. Such is our conclusion about familiarity with respect to code formation in the matching task. Thus, we take the position that an encoding mechanism is innocent of sensitivity to a stimulus variable until proven guilty.

If forced to defend our position, we might claim that it constitutes good science, but, in the end, it is probably more a matter of taste. Henderson takes the opposite position, arguing as if encoding mechanisms do respond to familiarity until they are conclusively proven not to. We want to make it clear that we are not accusing Henderson of bad taste in choosing his standards, but only of taste that is different from ours. The difference becomes very clear in Henderson's review of the literature, from which he concludes that a criterion shifting explanation of familiarity effects is not entirely tenable and a code formation explanation should therefore be preferred.

\section{Twelve Experiments and What They Found}

In his Table 1, Henderson lists the lexicality effects found in "same" and "different" latencies in a dozen experiments using various forms of the matching task. In four of the experiments, lexicality was represented by a contrast between orthographically irregular but meaningful acronyms and irregular nonsense strings. In the remaining eight, lexicality was represented by a contrast between words and orthographically regular but meaningless pseudowords. We will apply our standards to the results of each of these experiments.

First, there are three acronym experiments to consider, two by Henderson and Chard (1976) and one by Seymour and Jack (1978). In each of these experiments, an interaction occurred between familiarity (or lexicality) and decision type. An advantage for familiar stimuli occurred in making "same" decisions, but a sizable disadvantage for familiar stimuli occurred in making "different" decisions.

Second, in a similar category are two experiments using words, one by Baron (1975) and one by Chambers and Forster (1975, Experiment 1), in which an interaction again occurred, a familiarity advantage was again found in "same" decisions, and, again, the familiarity effect reversed in direction for "different" decisions. In the latter two experiments, however, the familiarity disadvantages $(-10$ and $-8 \mathrm{msec}$, respectively) were substantially smaller than those found in the three studies using acronyms. All of the above experiments, however, produced a type of crossover interaction that makes them highly suspicious as sources of data on code formation.

Third, there are three more word experimentsone by Barron and Henderson (1977, Experiment 3), one by Barron and Pittenger (1974), and another by Chambers and Forster (1975, Experiment 2)-in which interactions were found between familiarity and decision type but the effects of familiarity were positive on both "sames" and "differents." This is much more encouraging evidence for a locus in code formation than the five experiments described in the previous paragraph, but, unfortunately, the familiarity advantage in making "different" decisions failed to reach significance in any of these studies. The magnitudes of the effects were 3,12 , and $19 \mathrm{msec}$, respectively (and the corresponding familiarity effects on "sames" were 126, 55, and $42 \mathrm{msec}$, respectively). The last experiment is tantalizing. The 19 -msec familiarity advantage on "differents" would have been respectable had it been significant, and it is not very much smaller than the familiarity advantage on "sames," at least relative to the interactions that were found in the other experiments described so far. Nevertheless, the pattern of data does not quite make it into the "unambiguous" category if one holds to a hard line. Furthermore, the error rate, especially on "different" decisions, was significantly higher for words than pseudowords, leading to the suspicion that the familiarity effect in this study could have resulted from a speed-accuracy tradeoff rather than facilitation of code formation. 
Next, we have a word-pseudoword experiment by Taylor, Miller, and Juola (1977, Experiment 3). These results look very promising, since a significant familiarity advantáge of 200 msec occurred in "different" decisions in addition to the $240-\mathrm{msec}$ advantage in "sames." As pointed out by Pollatsek and Carr (1979), however, some of the pseudowords used by Taylor et al. give one pause (e.g., MHEET, RHEET, SNEPD, TAGRN), opening the possibility that this "familiarity" effect is at least in part an orthography effect instead. With that qualification, the experiment meets the standards we have described.

A second experiment in Henderson's list seems also to meet the standards. Bruder (1978, Experiment 3) obtained a $172-\mathrm{msec}$ advantage for very common (high frequency of occurrence) words over pseudowords in "same" decisions and a smaller but still significant 58-msec advantage in "different" decisions. Bruder's findings raise a number of difficulties, however. In the same experiment, she reports a comparison between high-frequency words and lowfrequency words, which constitutes another test of familiarity effects. In that comparison, familiarity produced a disadvantage rather than an advantage on "differents," although "sames" were still facilitated. Perhaps these two comparisons together should be taken as support for Henderson's view that lexicality itself is an operative variable: Although familiarity differences among words produced evidence consistent with criterion shifting, the difference between words and pseudowords produced evidence consistent with an effect on code formation. However, in addition to these other comparisons, Bruder compared less common (lower frequency) words with pseudowords, a converging operation on lexicality. This comparison resulted in a familiarity advantage in "different" decisions, but a familiarity disadvantage in "sames," the only effect of its kind that we know of in the literature. Bruder seems to have amassed support for both of the competing positions by obtaining both the competing patterns of data in the same experiment and another, much more unusual, pattern as well. Such internal inconsistency leaves us in doubt about the proper way to interpret the comparison of high-frequency words with pseudowords, on which Henderson focuses in discussing Bruder's paper.

So far we have considered 10 of the 12 experiments. We have concluded that seven of these clearly fail to provide unambiguous evidence for an effect of familiarity on code formation, that an eighth (Chambers \& Forster, 1975, Experiment 2) comes close but still fails, that a ninth (Bruder, 1978, Experiment 3 ) is internally inconsistent and confusing, and that a tenth (Taylor et al., 1977, Experiment 3) meets our standards with respect to its data pattern but may have some problems with stimulus materials. Henderson, however, accepts all of these experiments as evidence in favor of an effect on code formation (although he hesitates a bit on the three acronym experiments with large familiarity disadvantages on "different" decisions and on the word experiment by Baron, 1975, in which the 10-msec disadvantage on "differents" was somewhat comparable in absolute value to the 23msec advantage on "sames"). Why should this be?

Henderson's position is that a criterion shifting explanation requires that the disadvantage on "differents" be equal in size to the advantage on "sames"that is, he argues that a criterion bias in the absence of an effect on code formation would result in a completely symmetrical crossover interaction between familiarity and decision type. Since none of the studies in the literature produce a completely symmetrical interaction, Henderson argues that criterion shifting cannot be the sole explanation of any of these findings, and, therefore, it should be concluded that familiarity facilitates code formation in addition to whatever effects it may have on decision processes.

We have already pointed out one condition under which criterion shifting would not produce any kind of crossover interaction, much less a symmetrical one: if data relevant to each decision alternative were accumulated by an independent logogen-like structure that raced with the others to reach its criterion and control overt responding. But one need not accept this model of the decision process to predict that the facilitative effect of a criterion bias on "sames" might be larger than the inhibitory effect on "differents." If familiarity biases subjects toward responding "same" (for whatever illogical reason), and unfamiliarity biases them toward responding "different," the effect on "sames" will be larger than the effect on "differents" if familiarity is ever determined via a time-consuming search of stored memories. This is true because one would know that a string is familiar as soon as one found evidence of it in memory, but one could not know that a string is unfamiliar until one had finished searching all memories or exceeded a time limit and assumed unfamiliarity by default. Therefore, the visual matching process would more often be completed and the response would more often be chosen before familiarity became available to influence decisions when stimuli were unfamiliar than when they were familiar. Current theories of recognition memory (e.g., Mandler, 1980 ) hold that such a search is involved in assessing familiarity, although direct access to a familiarity index may at times precede or replace the search.

One could well object that these are not studies of recognition memory, and there is no compelling reason to believe that subjects determine familiarity as a part of the task. However, there is considerable reason to believe that the time required by phonological and semantic access varies with familiarity (Becker, 1976; Morton, 1969, 1979; Scarborough, Cortese, \& 
Scarborough, 1977), and that these codes could become activated automatically in the course of processing the letter strings. Incidental activation of phonological and semantic codes during the evaluation of visual information could work as a biasing agent (again, for whatever illogical reason). Such a biasing process would have properties like those of familiarity assessment per se that would tend to make the positive effect on "sames" larger than the negative effect on "differents." In light of this, we believe that asymmetric interactions are far less convincing evidence of the inadequacy of a criterion shifting explanation than does Henderson, and we are less willing than he to attribute familiarity effects to code formation when asymmetric interactions are present. This is especially the case if a change in experimental conditions that changes subjects' advance knowledge about the type of stimuli to be processed, such as blocking or randomizing stimuli by familiarity, has substantial impact on the presence or absence of the interaction. In Carr et al. (1979), stimuli were randomized by familiarity in Experiment 1 and a crossover interaction occurred. In Experiment 2, stimuli were blocked by familiarity and the interaction disappeared-in fact, familiarity had no effects at all in that experiment, although a robust main effect of orthography was found. We will therefore stand by the claim that the above 10 experiments fail to support a familiarity effect on code formation. However, since the interactions between familiarity and response type tend to disappear when familiarity is blocked, we agree with Henderson that blocking by familiarity is an important factor in conducting unambiguous tests of whether familiarity influences the quality of visual codes.

There are still 2 of the 12 matching experiments reviewed by Henderson remaining, and they present no problems in terms of effects on "same" vs. "different"' decisions. In 1974, Henderson obtained a significant advantage of acronyms over nonsense, amounting to $50 \mathrm{msec}$ in "sames" and $37 \mathrm{msec}$ in "differents." Taylor et al. (1977, Experiment 2) found a word advantage over pseudowords of $30 \mathrm{msec}$ in "sames" and $60 \mathrm{msec}$ in "differents." Yet, we object to both of these experiments. In order to explain the objection, we must discuss the use of laboratory tasks as tools to investigate the operation of particular encoding mechanisms.

\section{Tasks and the Mechanisms They Tell About}

Henderson begins his paper with reference to the large literature on word superiority effects, treating "same"'-"different" matching, tachistoscopic full report, and, later in the paper, tachistoscopic forcedchoice recognition as equivalent sources of data on factors that contribute to word superiority. This is a proper approach if one wants to study the word superiority effect as an empirical phenomenon. How- ever, we set out to study an internal encoding mechanism. Our assumption was that people's special perceptual facility with words is produced by the sensitivities of various word-processing mechanisms to various characteristics possessed by words. Our primary goal was to determine the characteristics to which one particular mechanism, visual code formation, is sensitive.

Thus, as already discussed, we needed to be reasonably confident that effects of stimulus characteristics observed in performance reflected code formation operations, not the manner in which decisions were made and responses selected. Beyond that, we needed to be reasonably confident that the effects reflected visual code formation. Thus, we needed a task for which there is clear evidence that performance is based on visual codes-the shapes of the stimuli-rather than phonological or semantic recodings. Consider, for example, tachistoscopic forcedchoice recognition. Even though stimuli are presented visually, effects of stimulus variables in this task are not necessarily indicative of the operation of visual encoding mechanisms. Hawkins, Reicher, Rogers, and Peterson (1976) set up a standard version of the task, but included a small number of trials on which the response alternatives were homophonic: Subjects had to decide whether they had seen CITE or SITE, REAL or REEL, POLE or POLL. Performance was barely above chance on these catch trials, even though subjects were quite accurate at choosing between the nonhomophonic response alternatives used in the remainder of the task. These data demonstrate that performance in tachistoscopic recognition is often mediated by phonological recodings of the latter strings (see also Mezrich, 1973; Smith \& Spoehr, 1974; Spoehr, 1978). Therefore, despite the fact that the word superiority effect found in tachistoscopic recognition is clearly perceptual in nature (Adams, 1979; Johnston, 1978, in press; McClelland \& Johnston, 1977; van Santen, 1979), it often arises outside the visual system, and one would therefore avoid choosing tachistoscopic recognition in order to study visual codes.

However, the investigator wishing to study visual codes might choose the matching task instead. A word advantage has been found in matching when the task required detection of a difference in case between two letters in otherwise identical strings, such as FOrM vs. FORM (Pollatsek, Well, \& Schindler, 1975). The most likely explanation is that something about words facilitates the perception of shape-that is, the visual code. Furthermore, two experiments have obtained no effect of homophonic "differents" when compared with nonhomophonic "differents," indicating that phonological codes were ignored in making decisions (Baron, 1975; Pollatsek, Well, \& Schindler, 1975), and one experiment has obtained no effect of synonomous "differents," indicating 
that semantic codes were ignored (Barron \& Henderson, 1978). All of these experiments used physical matching instructions with simultaneously presented strings arrayed one above the other

\section{$\left(\begin{array}{l}\text { STRING } \\ \text { STRING }\end{array}\right)$}

When that format is followed, then, the matching task appears, in general, to be a reasonable source of data on visual information processing, and, as long as results are free of criterion shifting, speed-accuracy tradeoff, and other decision-related effects, the task appears in particular to be a reasonable source of data on visual code formation. No other putatively visual task has been so carefully documented with respect to whether or not visual codes actually underlie performance, so we believe "same"-"different" matching is currently the best source of data on the operation of visual encoding mechanisms. (Because no gambler likes it when there is only one good game in town, documentation of the extent to which exclusively visual information is relied on in other tasks would be a useful contribution to the literature.)

We can now explain our objections to the remaining two matching experiments reviewed by Henderson. Taylor et al. (1977, Experiment 2) used successive rather than simultaneous stimulus presentation, with the first stimulus presented for $3 \mathrm{sec}$ followed by an 800 -msec interstimulus interval. The memory demands of successive presentation, especially given the long time during which the first stimulus was available for elaboration and rehearsal, make it quite possible that subjects relied on phonological or semantic codes for some portion of the trials, which means that the familiarity advantage found in the experiment may not be attributable to visual encoding processes. Thus, the locus of this familiarity effect is ambiguous. In Henderson's (1974) experiment, stimuli were presented simultaneously, but they were arrayed side by side rather than one above the other. The stimuli, which subtended a visual angle ranging from about .5 to about $1.25 \mathrm{deg}$, were separated by a visual angle that varied between about .66 and about 1.33 deg. Suppose that these strings were perceived by focusing the eyes on one, encoding it, and then moving the eyes to the other. This is not a farfetched thing to happen, since the total visual angle of the display, about 2.25 to about $3 \mathrm{deg}$, comes close to the horizontal perceptual span for completely accurate encoding during reading that has been identified by Rayner and McConkie (1977; Rayner, 1978). If this were done, then not only would the subject's scanning strategy turn the experiment into a functional equivalent of successive rather than simultaneous matching, but also the second string would mask the first if it fell on the same retinal coordinates (Davidson, Fox, \& Dick, 1973; Turvey, 1977). Therefore, the conditions of this ex- periment also make it possible that subjects relied (to an unknown extent) on phonological or semantic recodings, and the locus of its familiarity advantage is also ambiguous without further investigation.

After reviewing the matching literature, Henderson goes on to cite a number of tachistoscopic recognition studies as support for the position that familiarity produces perceptual facilitation. As will be clear from the preceding arguments, that may well be true, but the data are nonanalytic with respect to the question of what facilitates visual code formation because of the large contribution often made by phonological codes to performance in tachistoscopic tasks.

Besides explaining what we tried to do in our experiments and the kinds of evidence we wanted to obtain, we think that this discussion of tasks as tools makes a more general point. If one's goal is to explore the parameters of an observable phenomenon, such as the word superiority effect, then any task in which the phenomenon occurs is a useful source of data. But if one's goal is to identify the properties of a particular processing mechanism that underlies the phenomenon, then a different research strategy must be followed. One has to take pains to ensure that one is gathering data that tell about the specific mechanism under scrutiny and not about other mechanisms that are involved in the phenomenon but are of no interest to the investigation.

\section{Visual Code Formation and the Word}

At this point, we can reaffirm our previous conclusion. Although a number of experiments indicate that orthographic regularity facilitates visual code formation, and it is clear that familiarity can influence total processing time for speeded judgments, there is little definitive evidence that familiarity or meaning makes a difference to visual code formation. On the issue of familiarity, we are in the difficult position of arguing the null hypothesis. As Henderson points out, we might have reached a different conclusion had we chosen words or acronyms of higher frequency, pushing familiarity to its upper limit. ${ }^{1}$ We might also have concluded differently had we chosen stimuli of greater length, drawing out the processing required by the task and giving familiarity more time to work. Since the matching experiments that came closest to producing good evidence for visual familiarity effects used five-letter strings that were all fairly common (Barron \& Henderson, 1978, Experiment 3; Taylor et al., 1977, Experiment 3), whereas we used three- and four-letter strings, some (but by no means all) of which were not very common, this is a point well taken. Perhaps future research with more sensitive techniques will uncover an influence of past experience with a string of letters that has so far gone undetected. At the moment, however, our best guess is that, as far as words are concerned, the visual system can spell by the rules, but it can't remember very well. 


\section{REFERENCES}

Adams, M. J. Models of word recognition. Cognitive Psychology, $1979,11,133-176$

ANDERSon, J. R. Language, memory, and thought. Hillsdale, N.J: Erlbaum, 1976.

BAron, J. Successive stages in word recognition. In P. M. A. Rabbitt \& S. Dornic (Eds.), Attention and performance $V$. London: Academic Press, 1975.

Barron, R. W., \& Henderson, L. The effects of lexical information on same-different visual comparison of words. Memory \& Cognition, 1977, 5, 566-579.

Barron, R. W., \& Pittenger, J. B. The effect of orthographic structure and lexical meaning on "same"-"different" judgments. Quarterly Journal of Experimental Psychology, 1974, 26, 566581.

Becker, C. A. Allocation of attention during visual word recognition. Journal of Experimental Psychology: Human Perception and Performance, 1976, 2, 556-566.

Bobrow, D. G., \& Collins, A. M. Representation and understanding. New York: Academic Press, 1975.

BRUDER, G. A. Role of visual familiarity in the word superiority effects obtained in the simultaneous matching task. Journal of Experimental Psychology: Human Perception and Performance, $1978,4,88-100$.

Carr, T. H. Consciousness in models of human processing: Primary memory, executive control, and input regulation. In G. Underwood \& R. Stevens (Eds.), Aspects of consciousness. London: Academic Press, 1979.

Carr, T. H., Posner, M. I., Pollatsek, A., \& Snyder, C. R. R. Orthography and familiarity effects in word processing. Journal of Experimental Psychology: General, 1979, 108, 389-414.

Chambers, S. M., \& Forster, K. Evidence for lexical access in a simultaneous matching task. Memory \& Cognition, 1975, 3, $549-560$.

ConRAD, C. Some factors involved in word recognition. In J. W. Cotton \& R. L. Klatzky (Eds.), Semantic factors in cognition. Hillsdale, N.J: Erlbaum, 1978.

Davidson, M. L., Fox, M. J., \& Dick, A. O. Effect of eye movements on backward masking and perceived location. Perception \& Psychophysics, 1973, 14, 110-116.

Fonste R, K. Accessing the mental lexicon. In R. J. Wales \& E. Walker (Eds.), New approaches to language mechanisms. Amsterdam: North-Holland, 1976.

Hawkins, H. C., Reicher, E. M., Rogers, M., \& Peterson, L. Flexible coding in word recognition. Journal of Experimental Psychology: Human Perception and Performance, 1976, 2, 380-385.

Henderson, L. A word superiority effect without orthographic assistance. Quarterly Journal of Experimental Psychology, $1974,20,301-311$.

Henderson, L. Is there a lexicality component in the word superiority effect? Perception \& Psychophysics, 1980, 28, 179 184.

Henderson, L., \& Chard, M. J. On the nature of the facilitation of visual comparison by lexical membership. Bulletin of the Psychonomic Society, 1976, 7, 432-434.

JoHNSTON, J. C. A test of the sophisticated guessing theory of word perception. Cognitive Psychology, 1978, 10, 123-153.

Johnston, J. C. The effect of advance precueing of alternatives on the perception of letters alone and in words. Journal of Experimental Psychology: Human Perception and Performance, in press.

Keele, S. W. Attention and performance. Pacific Palisades, Calif: Goodyear, 1973.

KeELe, S. W., \& Neill, W. T. Mechanisms of attention. In E. Carterette \& M. Friedman (Eds.), Handbook of perception (Vol. 9). London: Academic Press, 1978

Mandlen, G. Recognizing: Judgments of previous occurrence. Psychological Review, 1980, 87, 252-271.
MCClelland. J. L. On the time relations of mental processes: An examination of systems of processes in cascade. Psychological Review, 1979, 86, 287-307.

McClelland, J. L., \& Johnston, J. C. The role of familiar units in the perception of words and nonwords. Perception \& Psychophysics, 1977, 22, 249-261.

Meyer, D., SchyaneveldT, R., \& Ruddy, M. Loci of contextual effects in visual word recognition. In P. M. A. Rabbitt \& S. Dornic (Eds.), Attention and performance $V$. London: Academic Press, 1975.

Mezrich, J. J. The word superiority effect in brief visual displays: Elimination by vocalization. Perception \& Psychophysics, 1973, 13, 45-48.

Monton, J. Interaction of information in word recognition. Psychological Review, 1969, 76, 165-178.

Monton, J. Some experiments on facilitation in word and picture recognition and their relevance for the evaluation of a theoretical position. In P. A. Kolers, M. E. Wrolstad, \& H. Bouma (Eds.), Processing visible language 1. New York: Plenum Press, 1979.

Newell, A. Production systems: Models of control structures. In W. G. Chase (Ed.), Visual information processing. New York: Academic Press, 1973.

Norman, D. A., \& Rumelhart, D. Explorations in cognition. San Francisco: Freeman, 1975.

PollatseK, A., \& CARR, T. H. Rule-governed and wholistic encoding processes in word perceptions. In P. A. Kolers, M. E. Wrolstad, \& H. Bouma (Eds.), Processing visible language $I$. New York: Plenum Press, 1979.

Pollatsek, A., Well, A. D., \& Schindler, R. Familiarity affects visual processing of words. Journal of Experimental Psychology: Human Perception and Performance, 1975, 1, 328-333.

Posner, M. I., \& Rogers, M. Chronometric analysis of abstraction and recognition. In W. K. Estes (Ed.), Handbook of learning and cognitive processes. Hillsdale, N.J: Erlbaum, 1978.

Posner, M. I., \& SNyder, C. R. R. Attention and cognitive control. In R. L. Solso (Ed.), Theories in information processing. Hillsdale, N.J: Erlbaum, 1975.

RAYNER, K. Eye movements in reading and information processing. Psychological Bulletin, 1978, 85, 618-660.

RAyner, K., \& McConkie, G. Perceptual processes in reading: The perceptual spans. In A. S. Reber \& D. L. Scarborough (Eds.), Toward a psychology of reading. Hillsdale, N.J: Erlbaum 1977.

Scarborough, D. L., Cortese, C., \& Scarborough, H. S. Frequency and repetition effects in lexical memory. Journal of Experimental Psychology: Human Perception and Performance, $1977,3,1-17$

Seymour, P. H. K., \& J JCK, M. V. Effects of visual familiarity on "same" and "different" decision processes. Quarterly Journal of Experimental Psychology, 1978, 30, 455-470.

Smith, E. E., \& Spoenr, K. T. The perception of printed English: A theoretical perspective. In B. H. Kantowitz (Ed.), Human information processing: Tutorials in performance and cognition. Hillsdale, N.J: Erlbaum, 1974.

SPOE HR, K. T. Phonological encoding in visual word recognition. Journal of Verbal Learning and Verbal Behavior, 1978, 17, $127-141$.

StERnBerg, S. The discovery of processing stages: Extensions of Donders' method. In W. G. Koster (Ed.), Attention and performance II. Amsterdam: North-Holland, 1969.

TAYlor, D. A. Stage analysis of reaction time. Psychological Bulletin, 1976, 83, 161-191.

TAYlor, G. A., Miller, T. J., \& JuolA, J. F. Isolating visual units in the perception of words and nonwords. Perception \& Psychophysics, 1977, 21, 377-386.

Treisman, A., \& Gelade, G. A feature integration theory of attention. Cognitive Psychology, 1980, 12, 97-136.

Turvey, M. T. Contrasting orientations to the theory of visual information processing. Psychological Review, 1977, 84, 67-88. 
VAN SANTEN, J. P. Evidence for a recoding explanation of the word superiority effect in tachistoscopic conditions. Unpublished doctoral dissertation, University of Michigan, 1979.

Wickelgren, W. Cognitive psychology. Englewood Cliffs, N.J: Prentice-Hall, 1979.

\section{NOTE}

1. We cannot resist commenting on Henderson's analysis of our stimulus materials. He says that we offer no evidence on the meaningfulness of our acronyms (although the meaningfulness judgments that were collected in Experiment 4 could be taken as one form of such evidence), and he goes on to say that inspection "suggests that several of these supposedly familiar and meaningful stimuli can only be discriminated from meaningless control stimuli after considerable deliberation." When we looked at the stimuli that Henderson (1974) used in his own study of acronyms, we felt much the same way-that many of his acronyms were obscure indeed. But we are not British, and the opinion that counts on the matte: is that of Henderson's subjects, who were British. Taking the acronyms from our study that he questioned, most Americans are very familiar with WPA as one of Roosevelt's job programs during the Great Depression. GPA (grade point average) is understood by all college students in the United States, and OSU is understood by the students at the University of Oregon, where we collected our data (it stands for Oregon State University, located 50 miles to the north). CPA, standing for certified public accountant, might be less familiar. UFW was a misprint that we failed to spot in correcting the galley proofs. The correct stimulus, UFO, stands for unidentified flying object, a phrase familiar to most young Americans. Finally, there is probably no resident of the United States over the age of 18 who is not (only too) familiar with IRS-the Internal Revenue Service, to whom we pay our taxes. An additional note: We performed a separate analysis, reported as a part of Experiment 2, on data from four very common acronyms with which all of our subjects would have been familiar (FBI, $A B C, C B S$, and $N B C$ ) and obtained all of the same results as in the overall analyses.

(Received for publication December 16, 1980; accepted December 22, 1980.) 